\title{
Cool, sunglasses and the modern woman: Icons of the 1960s
}

\section{Vanessa Brown, Nottingham Trent University.}

\begin{abstract}
This article considers the enduring appeal of certain iconic images of (sub)urban/e women of the 1960s: Audrey Hepburn in Breakfast at Tiffanys (1961); Black Panther Kathleen Cleaver; and 'Lolita' as depicted in the promotional poster for Kubrick's 1962 film. These are considered in relation to the idea of 'coolness', an attribute explored as problematic, yet generally desirable. Frequently perceived as a male attribute, even a male pathology, this article explores cool specifically in relation to iconic images of women, and their potential meanings both at the time of their creation and in the present day. It demonstrates how connections between coolness and modernity are articulated in imagery of women by the wearing of sunglasses, a material and embodied practise that allows acts of gazing to be nuanced in a variety of ways. At first sight, these images may have multiple, ambiguous and apparently contradictory meanings (from 'nymphet' to patriarchal refuser) but I will argue that viewing them through the use of sunglasses and the lens of 'modern cool' helps to refocus their power and continued, broad appeal as current benchmarks of still desirable, modern femininities, and therefore, their presence in a plethora of pastiches, consumer products and style discourses.
\end{abstract}

\section{Keywords}

Cool 
sunglasses

modernity

post-feminism

Kathleen Cleaver

Lolita

Audrey Hepburn

\section{Aims and context}

As part of an ongoing project exploring visual, material and embodied manifestations of 'coolness' within twentieth- and twenty-first-century cultures, this article presents a focused analysis of three iconic images of 1960 s women, ${ }^{1}$ critically engaging with existing analyses and with relevant theories of cool. Two of the selected images, the filmic Lolita (Kubrick, 1962) and the ubiquitous Audrey Hepburn as Holly Golightly in Breakfast at Tiffany's (Edwards, 1961), resonate widely with contemporary audiences, persisting as both easy commercial pastiche and sublime myth within the popular imagination. The other image, Kathleen Cleaver, communications officer for the Black Panther Party (BPP) in 1968, has been translated less into mainstream consumer forms but is nevertheless widely recirculated as iconic. All three, whether documentary, fictitious or otherwise, can be seen to have had lasting impact on fashion imagery and to 'epitomize' a particular 'fashion look'. All are known for their sunglasses and although very different, all can be described as expressions of 'modern' girl/womanhoods emerging in the 1960s, associated with greater independence and freedom from normative ideals. Much scholarly attention has been paid to these images 
previously, but this article explores how these images might be perceived as cool in relation to gendered articulations of modernity and the meaning potentials of sunglasses. It argues that the presence of sunglasses has increased the images' perceived relevance and currency for audiences at the time of their creation and continues to resonate with contemporary audiences in a shifting cultural and political landscape.

Therefore, the purpose is not to celebrate positive or 'progressive' interpretations of these images but more to consider what 'problems' they might symbolically solve for their fans, and especially, how the multi-layered meaning possibilities of sunglasses enhance the potential for these particular images to reach audiences with a whole variety of nuanced female ideals. Simultaneously, this contributes towards the study of the meaning of sunglasses as material-visual signifiers and towards the understanding of 'cool' in relation to female identity.

The article starts by briefly exploring the concept of cool and providing a short historical overview of key developments in the meanings associated with sunglasses before the 1960s, before moving on to consider the images of women, their place in the 1960s and their potential meanings today.

\section{Cool}

Cool is a slippery concept that has attracted increasing attention since the 1990s (including in the related terms of 'hipsterdom' and the emotional inscrutability of 'low' or 'blank' affect), but which still requires more work to comprehend its contradictory and multiple elements, and its historical mutations. For our purposes here, theories and histories of cool derive from several relevant places. First, cool has been seen as a response to the widespread cultures of technical rationality - the anonymity and chaos of the city, the alienation of mechanization and mechanized systems (e.g. Simmel [1903] 1964; Stearns 
1994; Mentges 2000; Liu 2004; Dinerstein 2013). There is also a material and aesthetic connection between cool and modernism. Second, cool derives from black American (male) survival tactics innovated against a modernity that also contained slavery and racism. Their stylized, detached behaviours and self-possessed aesthetics were then adopted first by the avant-gardes and countercultures of mid-century America (Mercer [1987] 1997; Macadams 2002) and then widely appropriated and commercialized (Tate 2003). Third, cool derives from an aristocratic demeanour of white European society that, along with the impertinent confidence of dandies (Walden 2002), who parodied and assumed aristocratic status without the birthright, informed fashion photography and cinematic nonchalance from the outset.

These trajectories have been discussed by authors from different perspectives but most agree that where cool emerged as a spontaneous, creative, rebellious response to challenging conditions, its potential to actually rock any systemic boats was mostly symbolic, and therefore proved easily containable by individualist consumer capitalism, eloquently argued by Frank in his book The Conquest of Cool (1997). Hence, scholars now largely agree that 'hipsters', male and female, are children of the 1960s cool counterculture, ideal neoliberal consumers who fuel capitalism with trends and novelties while espousing 'antiestablishment/anti-mainstream' or even an anti-capitalist rhetoric: cool might resemble rebellion, but recent history suggests that its political force is easily defused.

\section{Cool and sunglasses}

In previous research I explored how sunglasses accrued their varied significations of coolness between the first decades of the twentieth century and the end of the 1960s, when the connection was firmly cemented in popular culture (Brown 2015). Through the analysis of modernity's 'onslaught' on the eyes, the modes of perception and varied enactments of the gaze facilitated by certain temporal, spatial and social contexts in which sunglasses were 
fashioned and worn, a rough and roughly chronological taxonomy of cool is derived: the cool of mechanized speed (dynamic cool), engagement with technology (techno-cool), the culture of celebrity, self-fashioning and 'the good life' (glam-cool), the experience of life in subordinate, marginalized or 'deviant' groups ('outsider' cool). A final variant, 'ecliptic' cool, contains not the detachment of concealed rage or superiority, but emptiness, affectlessness and retreat from meaning.

Although these each contain multiple social and political configurations, what connects them - even as they might seem to be opposed - is the underlying sense of cool being a 'form of composure and self-possession', which suggests 'an idealized adaptation to the potentially disruptive forces of modernity' (Brown 2015: 159). These disruptions have not subsided. During the digital revolution, the speed of technology and fashion-driven change increased, these twin tyrants converging to bring increased pressure. That multiplicity of concurrent trends and 'choices', the cacophony of voices noted by Gergen in 1991, are now carried not just at the back of our minds, but in our pockets. Compulsive distractions chip away at the sense of self. As suggested by Haselstein, for an individual to be cool is, ultimately, to achieve 'a [...] convincing public self-presentation' (2013: 74), much easier said than done.

There are nuances to these arguments that I do not have space to explore here, but hopefully this overview presents cool, in its varied forms, as something prized widely because it is heterogeneous in origin and advantageous, and yet elusive, in modern conditions. Audiences might therefore sense relevant forms of cool in unexpected places.

\section{Male/female cool}

The literature of cool commonly focuses on men and masculinity: jazzmen, fighter pilots (Mentges 2000), motorcycle gangs and film stars such as Steve McQueen (Pountain 
and Robins 2000). Maybe this is everyday sexism - the cool women are just routinely ignored. But some critical analyses of cool and 'proto' cool figures, such as the dandy and the flâneur, have suggested that it just was not possible for women to be cool because their social position was much more precarious and tied in to biological and social roles of childrearing and familial responsibility (Fraimen 2003). Given that popular characterizations of cool are often anti-heroes, villains, profoundly anti-social and pathologically detached (no matter how 'desirable' they might otherwise appear to be) we cannot simply see this absence of women as negative. Indeed, the 'controlled affect' of coolness is sometimes defined as male emotional dysfunction culpable for certain kinds of real-life cruelty to women (hooks 2003; Majors and Billson 1992). The ubiquity of sunglasses in images of twentieth- and twentyfirst-century cool men is striking, working as highly economical external signifiers of an interior state of 'impressive' impenetrability.

The relative absence of analysis of coolness in women is, however, strange, given the quantity of 'cool' images of women produced in the same period. From non-smiling fashion models to game characters, spectacularly unemotional representations of idealized women permeate popular fashion and film, often telegraphed with shades. Embodying a cool demeanour is often presented by cinema as especially impressive in women, marked as unusual, as if its achievement is harder for the weaker, emotional, reproductive mind and body.

\section{Sunglasses 1920s-1960s}

Before we go on, I will sketch out some relevant milestones in the development of sunglasses as a popular signifier of cool. Significantly, sunglasses originally emerged as protection in industrial settings (specifically for 'furnacemen') and mechanized speed (railway glasses). High-fashion imagery of the 1920s alludes occasionally to 'goggles' as 
driving or flying accessories for women. They had strong masculine and modern connotations of technology, speed and risk, also being worn by the First World War fighter pilots and motorcycle police. Less obviously tough goggles were also promoted to 'the girl who sits on the sands' in the 1910s and the early 1920s, but sunglasses were absent from fashion imagery and seem not to have been considered feminine (Brown 2015). Even in the mid-1930s, a promotion for American 'Fosta' sunglasses featured the strapline 'Easy on the Eyes', triply signifying the prettiness of the girl, the attractiveness of the glasses and the benefits of eye-shading. However, the lenses that the girl wears look clear, deliberately omitting the dark tints of the actual lenses used in the product, thereby maintaining the open and unchallenging expression of traditional feminine beauty.

When sunglasses did appear in a fashion context, in a 1938 editorial by Louise DahlWolfe, for the avant-garde US magazine Harpers Bazaar, dark lenses surrounded by bright white frames sit directly in the centre of a composition with single-point perspective, making them the focus. Casual nonchalance merged with insolence (Edwards 1989) and cheekily appropriated aristocratic hauteur. The setting is undeniably modern; she is tanned, a tourist, in a minimal cotton dress, wearing something new, glossy and plastic, and clearly cannot be bothered to acknowledge the viewer.

In 1930s American popular culture, sunglasses were associated with elite leisure and sunbathing, and as a highly visible and relatively cheap tool for transforming appearance they quickly became signifiers of celebrity, mainstream glamour and aspiration central to the democratization of style and 'self-fashioning'. Unsurprisingly, they simultaneously suggested artifice, narcissism and hedonism, especially in women - hence their appearance in 1940s film noir, where femmes fatales wearing shades ostensibly masked (but revealed to audiences) their murderous lack of feminine emotion, their insincerity and the manipulative allure of the tantalizingly 'covere'd [sic] dish' (Heyl 2001). Sunglasses were a signifier of a 
fearful modern femininity, but they also developed connotations of predominantly male 'outsiderhood' associated with the idealized demeanour of detachment and self-possession typified by photographs of black American Jazz musicians, but also the beats, left bank intellectuals and gangsters. By the late 1950s, all these meanings could be referenced in further representations as sunglasses took on a world-weary, stylized absence with the frisson of dissent and critique. In A Bout de Souffle (Godard, 1960) sunglasses marked detached and 'poseurish' beatniks with performativity, nihilistic self-consciousness and superficiality.

These points are brief, but remind us that by the 1960s, sunglasses already had potent and multi-layered connotations, suggesting various 'ways of knowing' the modern world and ways of being in it. The politics of the gaze in respect of race, class, gender and sex could be played with in complex ways through sunglasses' capacity to give and take away access to the eyes: to interrupt or discomfit the onlooker, to appear to draw or deflect attention, to appear to be unperturbed - or plainly disdainful, to appear to be - one way or the other - 'on top'. As such, sunglasses had become a highly flexible and commercially appealing tool for image makers in a decade of massive cultural change for the west.

\section{A gazelle in sunglasses}

Audrey Hepburn has received considerable scholarly attention (Stacey 1994; Mosely 2002; Miller 2014; Finnane 2009) and the opening scene of Breakfast at Tiffany's, where she stands gazing into the window, take-out in hand, ${ }^{2}$ has been analysed by several authors. Her oversized, doubly dark Oliver Goldsmith 'Wayfarers' are visually arresting, and stills are highly sought after; a large black and white one dominates Gabriela Hearst's Manhattan bedroom, featured in Hello magazine (September 2016: 14). ${ }^{3}$ Reproductions are sold enmasse and digitally to custom order - on cheap phone cases, cushions and 'wall art', in bargain home-stores, high-end department stores and by numerous online retailers. At the 
time of writing, the same image was inspiring hand-made contemporary craft products appearing on the American Etsy, which tends towards minimal, lo-fi, hipster aesthetics. The enduring appeal of this image, across otherwise disparate taste groupings, is evident.

The glasses are a key signifier of the Audrey/Holly Golightly 'look'; many images of her currently on sale feature these glasses and refer to this scene. Sometimes the glasses stand alone to signify her or the film, despite the Wayfarer style having numerous other associations. Capote's novel states that Holly wears sunglasses habitually (1961: 89); yet scholarly attention to them has been scarce, and they were missing from the original promotional poster, ${ }^{4}$ suggesting that their value to the Audrey/Holly character and indeed the film may have been underestimated. Equally, although many studies evaluate Audrey's specific appeal, coolness is not considered, or at least, it is not expressed as such.

In fact, one of Audrey's defining characteristics is seemingly the opposite of cool her irresistible vulnerability. Angus McBean's photographic portrait crops Audrey's hair, ears and half an eye, leaving the other as the focal point, a piercing but unself-conscious gaze under the delicately arched eyebrow. It substantiates both Capote's description of Holly as 'not quite twelve', with eyes 'as clear as rainwater' (1961:89), and Lingis's haunting description of human eyes as 'liquid pool[s] [...] more naked than flesh without pelt or hide [...] a substance susceptible and vulnerable' (1994: 171). If this is true, Audrey's eye is surely a well of purest $\mathrm{h}_{2} \mathrm{O}$ that you might contaminate just by looking.

\section{Alone in the city: Not striding but dawdling}

However, although known for her vulnerable face, many of Audrey's defining films show her 'at home' in the city, that signifier of modernity, place of onslaught on the senses, anonymity and inhuman pace, which both demands and rewards greater detachment. Simmel predicted two likely responses to urban overstimulation - the blasé and the neurasthenic. The 
'blasé' response arguably implies two things - a deadening of the ability to respond, plus a certain caché or sense of sophistication through world-weary familiarity with the 'advances' of modernity. Audrey/Holly's response to the city is therefore relevant to how she may or may not be perceived as cool. In Breakfast at Tiffany's, sunglasses work as what Goffman called 'involvement shields' (1963: 39), devices affording her avoidance of numerous and potentially hazardous encounters with others, slipping them on as she expertly ducks out of trouble and slinks away, like the cat that she is so often compared to (Miller 2014).

But in the iconic image of Audrey/Holly considered here, she is just idly gazing at stuff in the window. French's analysis of Audrey/Holly as 'flâneuse' (2016) reminds us that female 'window shopping' is too engaged for the 'mastery of the city' embodied by the 'triply detached' (Shields 1994: 77) male flâneur (another type, such as the dandy, whose behaviour presages aspects of the twentieth-century cool demeanour).

Furthermore, as a woman using flânerie to evade her clients' amorous advances, she cannot quite epitomize the supremacy and invisibility of the flâneur, who hooks up and takes leave at will. If we imagine the context of this Tiffany's scene without its Hollywood allure, and without its mythic status, we face what should be a vulnerable moment. It is 5am, she is alone, presumably tired, possibly hungover, possibly depressed (since this is where she escapes the 'mean reds'). She is exposed, in inappropriate clothing. But actually, it is bewitching that she does seem entirely unconscious of her risky environment. Perhaps the sunglasses give her a feeling of protection, of being 'behind' something, while blotting out signs of tiredness or emotion, and toning down the contrasts of a harsh world.

Both Radner (2013) and Postrel (2013) have explored the symbolic modernity of fashion images that depict women brazenly moving through urban space, but Audrey is not really 'striding'. Like the flâneur with his turtle on a lead, she is dawdling, blasé. 


\section{Cool waif}

This dawdling also enhances Audrey's 'child-like' quality, noted by both Barthes and De Beauvoir in the late 1950s. For Finnane (2009), Holly Golightly exemplifies the late 1950s/early 1960s waif type with five aspects, of which the 'child-woman' is one. The massive sunglasses make her 'elfin' face look even smaller, referencing the comedy of children emulating the sophistication of adults. But can 'the child' be 'cool'? Arguably they can; Finnane describes the child-woman as 'indifferent', 'changeless' and 'forgetful' (2009: 143), suggesting absent-minded absorption, inability to mature or be responsible. Sunglasses on a grown woman, in this kind of context, can underscore the irresponsible narcissism of girlhood. Naivety can also pass for nonchalance, especially when the eyes are ambiguously masked.

The 'blotting out' of Audrey's eyes (Capote's own phrase) with sunglasses decommissions a principal signifier of her femininity, replacing it with a signifier of technical rationality - a prosthetic in fact - muting perception of the other, and inhibiting emotional connection (1961:17). The 'Wayfarer' style is unisex, and dark colours tip the balance of these moments towards the 'androgyne' aspect of waif identity that Finnane claims implies a casual disregard for the rules and conventions of traditional femininity (2009: 146). This strong hint of emotional control, armoured by modern plastics in androgynous form, cannot be denied, even if it also reveals the weighty aggregate of Audrey's remaining femininity.

The waif is, for Finnane, also constituted from elements of 'the gamine' and the 'beat girl', bringing further hints of cool rebellion and rejection of dominant rules to possible interpretations of this image. She describes Audrey/Holly's glasses as a sign of 'beat girl' status, 'morally ambiguous', a statement of 'concealment' and 'unorthodoxy' (2009: 145). (Dark glasses always complicate the truth because they cannot help but announce the fact that 
you are covering something up.) Holly seeks escape from convention, as many of the 'single girl' types of the 1950s and the early 1960s did. Finnane aligns these elusive and evasive 'trickster' figures with the vagabond, the hobo and the picaresque. In the context of modern America, there is a correlation here between this 'anti-bourgeois vagabond' and Merton's taxonomy of 'responses to anomie' used by some cool theorists (e.g. Majors and Billson 1992). Merton's 'retreatist' is a type who backs away from the approved goals and the means in modern society, but may nevertheless become a fantasy hero, despite apparent failure. 'His' resulting 'loneliness' may be read as cool, as a defiant act of self-possession, a choice (Merton1967: 209). (Admittedly, this reading of Holly does downplay certain other significations that present her confusion, vulnerability and the 'predicament' that she is in, but there is enough material to make this a preferred reading for some audiences, especially if her image is detached from its context and the narrative.) Dark glasses self-exclude a wearer from the immediate social scene, while alluding to a complex array of other significations in this case, the worlds of modern glamour, criminality and existential crisis. The Audrey/Holly persona perhaps more accurately stands between two of Merton's other adaptations to anomie: the 'innovator', for whom the socially sanctioned end (glamour, the appearance of wealth) justifies the socially unacceptable/criminal means (courtesanship), and the rebel, who rejects the goals and the means, creating a new set, in this case, a form of bohemianism.

\section{Cool woman}

While this might raise questions about whether women can 'retreat', supporting Fraimen's conviction that cool is positioned against the feminine (2003), there is room to question the privileged association between masculinity and coolness. For Fraimen, what coolness most runs from is not femininity but the maternal. Furthermore, one cool forbear is the white, European aristocratic hauteur of perfectly straight-backed poise and unflappability, 
signified by the steady, disinterested gaze of superordinate rank, seen in the fashion photography of classics such as Horst. P. Horst. Here class intersects with race. As an authentic European aristocrat, Audrey brings elements of this to any role. Her childlike combination of playful cheek and vulnerability often counteracts it, but in the dark glasses, motionless before the window, her gentle composure can look much more like white female hauteur. This may especially be the case when considering the contrast between her effortlessness and American actresses' exaggerated performances of nonchalance as blasé but fleshy sex appeal. As Lewis states,

In their unavailability and aloofness, both past and present archetypes of the idealized white woman lend easily to coolness: she is effortlessly detached from normality, her style is one of resistance to mortal humanity, her beauty implies narcissism, she is a creature who exists for hedonism. (2011: 191)

Lewis also identifies potentially cool qualities of emotional restraint, demureness and ethereality as part of stereotypical and traditional femininity. Gundle's discussion of the courtesan as an early exponent of demi-monde glamour also speaks of impressive detachment. Part of the appeal of the courtesan was her remoteness, but also her deviance, and her original but convincing performance of self-fashioning in the modern world (2008).

\section{Cool glamour}

So, while the narrative may reveal Audrey/Holly to be anxious, volatile and vulnerable, the Tiffany's moment, like many others, notably celebrates her impressive 
embodiment of composure, nonchalance, the blasé, the elusive and the detached. Even hiding behind sunglasses has the caché of being a glamorous casualty of the modern scene. But they also present an impermeable and reflective outer surface of what Roelstrate called 'transparent opacity' (2010: online), redoubled by the baffling sparkle of layers of reflection in the shot. This scene resembles many cinematic mirror shots, routinely used to signify the instability and artifice of female identity. In the (colour) film, we can just see her eyes through the lenses, a hint of the (real?) Audrey to come. But the fabrication of sealed perfection attracts and deflects, just as Gundle says glamour does. Glamour can be cold - he describes it as a shiny surface, a mirror, a protective coating, a screen. Whatever her inner state, her outer surfaces are like an external skeleton, holding her up.

Also signified by the image - if not the narrative - is the coolness of effortless ability to deal with the demands of fashion. It may not be cool to seem to slavishly follow fashion (Brown 2013; Michael 2015), but as suggested earlier, expert competence with - or against fashion suggests admirable skills of adapting to change, while still presenting that convincing sense of self.

\section{Contemporary 'takes'}

So far I have identified the resources for audiences to perceive cool in Audrey/Holly in the Tiffany's scene by exploring the narrative, connections with cool theories and the potential meanings of sunglasses within the text. These meanings were available then and are still available now, but the popularity of Audrey/Holly's image is now independent of the film, as we might expect of an image described as 'iconic'. The reproductions and re-workings potentially emphasize different readings of the film, or just of the image, where it floats free of the narrative and derives its meaning from other contextual factors for contemporary audiences. Not only do these pastiches and prints deploy images that feature sunglasses 
(which in itself suggests that perhaps female coolness is a desirable value perceived either in the film or the stills), but aesthetic changes are also made that bring out different cool nuances. A good number of dress-up kits, new depictions and descriptions of Holly/Audrey misremember key details, giving her curves, and the more obviously feminine 'cat-eye' sunglasses. Conversely, many exaggerate the sense of blasé detachment and emotional control far beyond what fans and scholars 'know' of Audrey's star-text. This is often achieved simply by printing in black and white (although the film is in colour) and by the precise choice of still. In colour, her glasses are actually dark brown tortoiseshell, with not entirely obscure lenses, but in black and white the total effect becomes starker, especially if the contrast is exaggerated, which it often is. The view from inside Tiffany's window, revealing Audrey's be-sunglassed face square on, can be read without any knowledge of the film, as composed self-possession or as aspiring, glamorous, feminine woman. The side view from behind - of her gazing into the window, is perhaps the least vulnerable - no sign of her eyes whatsoever, and the glasses look heavy, black and square. She is the unwitting object of the gaze, but the sharper angles make for stronger body language, especially when reduced further to a single-colour screen-print effect, as in some of the products. ${ }^{5}$ These evoke the coldly ironic, low-effort/high-speed stencil graffiti of the 1990s typified by Banksy, sold now as 'vaguely counter-hegemonic' interior décor. Some emphasize the 'alternative' signifiers of black, smoking and sunglasses, even adding full tattoo sleeves.

In a postfeminist, post Sex and the City context, this image speaks to women who want mobility, self-possession (as Holly says - 'you can’t own me'), freedom from convention and adventure - and to those whose chosen adventures consist mostly of acquiring the accessories to a life of 'democratized' fashion luxury (of which expensive sunglasses are also a token). 
With its inscrutable gaze, self-absorption and 'vaguely countercultural' ethos, however, it also contains elements of the 'cool postfeminism' that Lewis says connects the 'nihilism and dispassion of cool' with 'postfeminist blankness and lack' (2011:191). Stacey's analysis of the contemporary mode of 'flat affect' (2015) compares Audrey's 'gamine' with Tilda Swinton's 'androgyne' performance, stating that Audrey's 'waif-like vulnerability [...] lacks the self-possession' that marks Swinton's 'off gender' appeal, and this is true; however, I would argue that as an isolated image (and for its time) her tall, tubular figure, composed body and sunglassed face do allow a reading of self-possession and flattened affect that may contribute towards its longevity and breadth of appeal.

\section{Lolita}

The image of Lolita, derived from Kubrick's 1962 film of Nabokov's 1958 novel, is another trope of femininity emerging from 1960s pop culture with similar longevity. Also a childwoman, 'Lolita' is not so much a celebrity-icon as a mythical type of 'sexually precocious girl' and a graphic 'meme' based on Bert Stern's photograph for the promotional poster that, unlike the film, features the iconic heart sunglasses and lollipop. ${ }^{6}$ Vickers calls this an abusive version of Nabokov's Lolita, a form of betrayal to the character, and to girls in general (2008: 8). For Vickers, the sunglasses suggest qualities that increase Lolita's agency in the relationship: a tool of seduction. How this works, and what else they might mean, is complex.

For if Holly uses sunglasses to evade her 'clients' and any other unwanted engagements, Lolita's draw much more heavily on the conventions of the femme fatale. She is a 'fille fatale' (Hatch 2002). The bright red, up-swept, heart-shaped frames capture the playfulness and romantic innocence of girlhood, the questions around her identity, her 'dangerous' mystique - and the tawdry glamour associated with 'cheap' commercial 
sexuality increasingly available after the second world war, suggesting malicious intent, manipulation, knowing femininity. Carter and Michael say that the sunglasses in this image afford a 'fleeting partial gaze' - an enactment of the gaze that dramatizes the giving and taking away of access to the eyes, creating a complex 'invitation'. In the poster, as in the sunbathing episode in the film, she interrupts and steadily meets the voyeur's gaze head on which, with anything like a slight smile or open body language, says - I know you are looking at me, and I do not mind. Closing off the eyes draws attention to the lips, parted by the lollipop; this objectifies the body, as many near-naked images with shaded eyes do. Is wearing sunglasses an invitation to gaze at her body? Ironically, in Wilson's 1999 study, a female focus group participant said that wearing sunglasses made her feel less vulnerable to male gazes when exposed on the beach. A male participant, however, stated that sunglasses on a bikini-clad woman on the beach encouraged him to look, with an 'almost pornographic' effect. Indeed, when sunglasses obscure a woman's eyes, it could allow a voyeur the fantasy that she might already be looking desirously at him. (Sunglasses known as 'Boywatchers' emerged later in the 1960s, cheerily commodifying this hope.)

This 'peeping' over an 'involvement shield' could conversely be interpreted as modesty, interest in the other that is hindered by shyness, anxiety or a lack of entitlement, or a knowing performance of such. Or, in the film poster genre, it could be an appeal from behind a barrier, from inside a trap. The steady and straight eye contact of the image in the poster, with an otherwise expressionless face, may do this in a way that other images from Stern's more suggestive shoot simultaneously published in Look magazine definitely could not.

Much else could be said about the use of sunglasses in excusing the erotic gazes that hit Lolita, but this is enough to demonstrate the extent to which Lolita's image is troubling to read as coolly aspirational. The 'nymphet' in red or heart-shaped sunglasses is a trope that 
has been widely copied and indeed celebrated (Laing 2018) by Ellen van Unwerth, notably with Kate Moss in Vogue Italia magazine (1992) and by Lana Del Rey in her 2012 album and associated photos ${ }^{7}$; even image bank Shutterstock offers a 'Sweet Lolita' category. Numerous sunglass models are styled and named after her - usually upswept, vaguely retro, often heartshaped, often red, a recent example being The Last Lolita by lespecs (2017/2018), 'inspired by the mischievousness of Sue Lyon' in the film. Why women continue to buy into this visualization of this trope is clearly complicated, but what is cool about Lolita?

Evidently, sunglasses already had strong connotations of 'coolness' in Europe and the United States, which they could potentially bring to any image. But how does this particular context nuance it? De Beauvoir states that the 'child woman' was a form of erotic exotic searched for by men in the period when the critical difference between men and women was waning (Finnane 2009: 143). So perhaps the wider context of uncertainty about changing roles for women is also relevant here, fear, not just of being seduced by an underage chick, but of what girls and young women might be capable of more generally. Where Dolores' story has been denied or forgotten, the risky/tricksterish connotations of sunglasses could more broadly signify the excitement of untapped potential, of transgressions of conventional femininity. Contemporary manifestations do not all retain the 'peeking'; some, like 'The Last Lolita' by lespecs, seem to emphasize blocking, mirrored lenses literally 'putting it back on you' and an ice lolly held away from the face. ${ }^{8}$ Some, like Unwerth's, seem to make space for a lesbian gaze. The 'cool' of the 'girly' Lolita image in heart-shaped glasses takes it beyond the glorification of child abuse, seduction or flawed metaphor for female power over men.

Although the glasses themselves are not the dark, androgynous lenses and frames of the unisex/masculine Wayfarer, rather, frivolous signifiers of love, we cannot assume that this is straightforward: $d o$ the frames mean 'I love you'? In cartoons and contemporary emoji, hearts for eyes mean exactly that. But we also know that the covered eye suggests deceit, and 
a highly controlled mind and body. If the frames themselves 'express' an emotion - it is a mass-produced and mechanical one that belies the unstable ebb and flow of real affective states. This 'baldness' of statement suits the image to irony, a commonly identified aspect of cool cultural 'expression', closely linked to detachment and self-consciousness in a postmodern world (which sunglasses had already connoted in 1957's A Bout de Souffle). This quality makes Lolita's image an especially useful postfeminist plaything.

As mentioned previously, cool has recently featured in discussions of postfeminism: first, in thinking of coolness in the sense of hyper-individual consumption (Gill 2016), second, as a function of 'flat affect' (Stacey 2015), 'underperformativity' (Berlant 2015), (including underperformance of gender) and - although not expressly stated as such potentially in the concept of 'radical frivolity' (Nathan in Willson 2015: 201).

Indeed, in a 'postfeminist' era, girliness has been viewed as a retreat from feminism based on assumptions that the major battles have been won, a reclamation of overt femininity as 'empowerment' (signs of female professional and financial success - the 'Manolo Blahniks', etc.), but an empowerment that reinforces previous problematics and that supports the consumerist status quo, thus failing to acknowledge the inherent inequalities of capitalism (Gill 2016). This fits with the least provocative forms of cool; i.e. cool as success within the goals and the means of modern society, as in 'yay, I have all the stuff everyone else I compare myself to currently wants, therefore I'm really cool' (Dar Nimrod et al. 2012). In a slightly different play on this, sunglasses exaggerate the pneumatic toughness of hyperfemininity - personified in recent years by Paris Hilton and co. This type of narcissism could be an aggressive refusal to have femininity denigrated - by men, feminists or whoever, or indeed, an apparently evasive - but actually firm - refusal to ardently present female subjectivity as serious or intelligent. This slip, from one possible meaning to quite another, tips the balance to Dar Nimrod et al.'s 'contrarion' cool (2012). 
In fact, this is one of the core stylistic weapons of cool groups. Pountain and Robins call it 'making a virtue of what might be used to exclude you', that is, exaggerating the focus of negative attention and presenting it - in a carefully mediated manner - as a battle cry (1999:8). Rather than down-playing femininity, 'girly' glasses amplify it, negating 'good taste' and 'good ordinary girl' qualities of thrift and work. The heightened state of female narcissism implied here circuits back into the historical mythology of 'letting them (me?) eat cake' of privileged aristocratic excess and nonchalance. This 'radical frivolity' defies others to be foolish enough to judge by appearances and take the consequences (as does the unapologetically pink and fluffy Elle Wood in Legally Blonde [2001]), but this also slides into the casual nihilism of Coppola's heroines and their 'low' or 'blank affect'. This is well illustrated by Wildfox's 2016 much 'repinned' promotional photography for their sunglasses range that drew heavily on Coppola's film Marie Antoinette, with bored pastel princesses in powdered wigs and dark, glossy shades.

Another dimension of this is 'underperformativity', discussed by Lauren Berlant in her analysis of another child abuse narrative (Mysterious Skin, 2005), where blankness stands not only for the (Hepburn-esque) impression-ability of a child but for a kind of generational bemusement that anyone older might see things as meaningful, or feel anything so straightforward as an emotion. The main character is described as 'the ultimate beautiful outsider' who displays 'nonchalance' towards danger (IMDB 2018). Berlant states that by 2005, 'under-performativity' was 'a resource for many across generations and social locations' with which to 'withdraw into whatever "whatever" style works to maintain relationality in some way, while keeping things apprehensively, hypervigilantly, suspended' (2015: 211). Whatever the political significance of these kinds of subjectivity (conservative psychological 'workarounds' as they may be) this may well be where the power of the Lolita image now lies - in the polyvalency of the image around femininity, agency, manipulation of 
the male gaze, glamour, irony and the continued resonance of cool as a sign of 'controlled affect' that implies impressive self-possession.

\section{Panther $[\ldots]$ in dark glasses}

In the final image, articulations of power and mediations of the gaze are significantly different. Kathleen Cleaver, Communications Officer for the BPP in the late 1960s, is a 'public persona' whose image featured widely in 1960s American news media and BPP's own communications, documented by photographers (and filmmakers) whose work now features in lush BPP anthologies. Style bloggers, culture journalists and academics all respond to the afro, dark glasses and black jacket or polo neck that typified Cleaver's adaptation of innovative Black Panther style. One of the most striking images, attributed to Black Panther associate Roz Payne, shows her addressing a crowd, with a microphone, unsmiling in her shades. ${ }^{9}$

This use of sunglasses had a very clear and material political agenda, anchored by the clarity and seriousness of Kathleen's communications, the relative sobriety of her clothing and the activism of her group. The BPP engaged in protest, which upset the status quo, organized and funded programmes to improve black children's welfare and they defended themselves with guns. Their improvised 'uniform' was used to signify 'coherence' and solidarity with other 'third world' anti-colonial guerrilla organizations (Phu 2008:169); aesthetically, they worked to create a 'counter-hegemonic gaze' (Hughey 2009:36). In this context dark glasses signified not just attitude, but action, and were capable of bringing together numerous relevant ideas.

As in images of black jazz musicians, the dark glasses intensify the signification of blackness, again 'making a virtue' of what might be used to exclude (Pountain and Robins 1999: 8). A woman identifying as black, but with pale skin, light green eyes, and a 'middle 
class' background, Cleaver's style connected her with the BPP community, many of whom were women, but also situated her appearance as 'Black and Beautiful' - especially in monochromatic news media. Black clothing and black, afro hair also signified 'blackness' in this politicized context, in addition to connecting with the subcultural and sartorial avantgarde heritage of those jazz innovators, merging with references to white appropriations of those styles in the 1950s and the 1960s. Cleaver's clothing references minimal 1960s Chanelstyle separates, beatnik androgyny and elements of African heritage. Mercer says that BPP 'militant chic' displayed 'inherent semiotic instability', highlighting the dynamic of appropriation and re-appropriation. Mercer emphasizes the urbane, freedom-seeking, rebellious modernity of the look, refuting the idea that the colour black or afro hair simply signified anything 'natural' ([1987] 1997: 42).

Mercer argues that sunglasses helped deflect the white, hegemonic gaze, as they had in jazz clubs, where black performers used them onstage, concealing the eyes, while knowingly displaying the fetishized body. Carter and Michael's 'anti-gaze' (2004: 275) describes vision that has seemingly been deliberately limited by sunglasses, announcing that the world beyond them matters little. In racist interactions, this provocatively disrupted the normal codes of deference and demeanour (Goffman [1967] 2005]: 64). In jazz, dark glasses also suggested alternative, secret or higher knowledges (of life, spirituality, drugs, art, music, sex) that underpinned numerous manifestations of cool, in a modern inflection of the blind seer whose vision is not clouded by the immediately apparent. On Cleaver, these connotations could be mobilized as refusal to be known both as a black woman and as a conventional politician. Loudspeaker in hand, a dark silhouette against a white ground, she gazes off out of the frame, a 'pioneer' - but with sunglasses. Where earnest, heartfelt messages - or performances of those - uttered by politicians are habitually made with engaging eye contact, Kathleen would not play ball. To the white media and government, the 
sunglasses are a sign - of concealed strategy, steely resolve, apparent disregard for rules and an intimidating, youthful competence with how the world now works, through the manipulation of image. Not seductive glamour, but the same push me/pull you, inviting speculation and instilling both respect and fear. Connotations of modern, techno-rational masculinity and 'alternative' femininity were heightened on Cleaver, where the sunglasses were accessorized not with pastries or lollipops, but with a loudspeaker - and in Alan Copeland's 1968 'at home' portrait, a gun.

The gun, which also appears in much-reproduced images of Cleaver, brings out an opposing possibility to the anti-gaze, which is that Cleaver sees everything. The gun tells us that she may be looking for something to aim at, but we cannot tell whether or where. A 'panoptic gaze' is depicted here (Brown 2015: 53). Standing in the doorway of her home with a rifle, the traditional/natural woman's proud display of domestic femininity is strikingly reconfigured. She wears black leather, too - a fabric particularly laden with connotations of techno-rational cool via its association with speed and human assimilation of the machine (Mentges 2000).

At the time, Tom Wolfe memorably coined the term 'militant chic', describing a 'fashion' for militancy among privileged liberals, employed to lend depth to otherwise frivolous personas (Rhodes 2017). Indeed the BPP look reified into a fashion - which was readily 'demonized' on men and sexualized or trivialized on women in the mainstream media (Raiford 2011), with its generally 'fetishistic' possibilities (as in Beyoncé's 2016 Superbowl performance, flanked by black robotic Tiller girls in leather hotpants, croptops, berets and afros). BPP women, who simultaneously sought female liberation, destabilizing gendered roles in the party where possible, were still reduced in cultural memory to their appearance. British journalist O’Hagan, reviewing Howard Bingham's Black Panther portrait anthology, described Cleaver as 'young and beautiful', 'the unexpected star in dark glasses and leather 
boots' (2009: online). As Angela Davis put it, a single generation later 'I am remembered as a hairdo' (Phu 2008: 167). Hairdo or sunglasses, the impact of BPP aesthetics is not disputed, but as with any revolutionary aesthetics, its effects are less clear, and like sartorial rebellions before it, it lost its 'edge' and wound up on the buffet table of style. It is beyond the scope of this article to enter the debate on the efficacy of style as a political strategy, but the 'coolness' in the McLuhan sense, of sunglasses, their ambiguous function as a blank screen for projection of fear and desire seems likely to have been both friend and foe to the cause.

Nevertheless, Cleaver's image is a representation of 1960s womanhood that genuinely transgressed then, and still seems to now. The rally image was used by Sawyer Studio's poster for the 2015 documentary film Black Panthers: Vanguard of the Revolution (Nelson), ${ }^{10}$ and with good reason. Follow her still-striking 'style' down any Internet rabbit hole and you do end up discovering a woman - one who built on her experiences to become a law professor - whose image stands for the admirable aspects of the whole movement.

In 2016, Essence magazine described Halloween costumes referencing BPP members and civil rights protesters as 'woke' (meaning 'woken up', 'raised consciousness', aware of the social and political implications of things, something that sunglasses have signified in films such as The Matrix). In a final twist, the very struggle between black men and women and the devil of representation is perhaps suggestible in the image of someone in shades. Raiford's 2011 book about the complexities of photography in the African American freedom struggle was entitled Imprisoned in a Luminous Glare. What more obvious signifier for that state? The frustrations with being 'reduced' to a surface are understandable, but perhaps what strikes people as powerful about Kathleen's image is not just its graphic immediacy or conformity to a beauty ideal. However 'sexy' they may be, what the images of Black Panther women most definitely were not is 'child-women', nor seductresses, nor symbols of financial success. Kathleen's image of course mobilizes the cool of black American experience, the 
controlled affect, the rebellious 'outsider' cool of disrupting the politics of the gaze in multiple ways, and of having the courage to invent new goals and new means, while demonstrating superior competence with modernizing processes. It is powerful because it suggests supreme bodily and mental composure in an extreme example of what Goffman called 'fateful' situations ([1967] 2005: 181) and intelligence. Not the nerdy, 'indoorsy' intelligence still associated with spectacles, but the intelligence associated with world-view that leads to action, and that is not deceived, distracted or bedazzled. Evidently, images of such female intelligence are still in short supply, making Cleaver's image all the more engaging.

An aesthetic quality enhanced in all these images to a degree is one of what could be loosely termed impermeability. The smooth, dense, shiny materiality of the sunglass frames and lenses could be analogous to an idealized skin, one that protects from, assimilates to and signifies to others - a privileged relationship with modernity. This quality is what Mentges describes in her article about the modern cool of fabrics worn by the First World War fighter pilots (2000), and is perhaps also what Gundle alludes to in his assessment of modern glamour (2008); it is also what Cheng refers to in her analysis of the relationship between European modernist architects and Josephine Baker - the search for a 'superhuman' Second Skin (2010).

\section{Conclusion}

This analysis demonstrates the significance of suggestions of coolness in the appeal of these 1960s women, a quality that has previously been somewhat overlooked. Considering coolness, and how it may be signified by sunglasses enables us to see qualities in common between the aristocratic waif, the nymphet and the activist. Sunglasses' ability to allude to 
alternative forms of consciousness, resistance, rebellion and deliberate withdrawal, flat or controlled affect makes these images especially open to both feminist and 'cool postfeminist' re-readings and appropriations, and indeed their recirculation and adaptation in particular ways since the 1960s suggests that they are screens for projections of variations of cool female identity as much as they might be literal celebrations of specific (problematic) embodied narratives.

The ambiguous position of cool as a largely symbolic form of rebellion that some suggest is now the principal legitimating narrative of capitalism (McGuigan 2013) complicates the route to any simple conclusion about the political value of these interpretations. But they do point to some significant aspects of what men and women who consume these images so enthusiastically might be aspiring to: that special invulnerability, the ability to remain composed, to 'keep it together' in the face of constant challenges to the sense of self, change, increasing complexity and distraction.

\section{References}

Berlant, L. (2015), 'Structures of unfeeling: Mysterious Skin', International Journal of Politics, Culture and Society, 28:3, pp. 191-213.

Brown, V. (2013), 'Is it cool to be fashionable? The instabilities of fashion and cool', conference paper, Fashion: Exploring Critical Issues, Oxford, 5 September, http://www.inter-disciplinary.net/critical-issues/wpcontent/uploads/2013/09/vBrown_wpaper-fash5.pdf. Accessed 5 September 2014. 
Academic.

Capote, T. (1961) Breakfast at Tiffany’s, New York: Signet.

Carter, S. and Michael, M. (2004), 'Here comes the sun: Shedding light on the cultural body', in H. Thomas and J. Ahmed (eds), Cultural Bodies: Ethnography and Theory, London: Wiley Blackwell, pp. 260-82.

Cheng, A. C. (2010), Second Skin: Josephine Baker and the Modern Surface, Oxford: Oxford University Press.

Dar Nimrod, I., Hansen, I., Proulx, T., Lehman, D. R., Chapman, B. P. and Duberstein, P.R. (2012), 'Coolness: An empirical investigation', Journal of Individual Differences, 33:3, pp. $175-85$.

Dinerstein, J. (2013), 'The mask of cool in postwar jazz and film noir', in U. Haselstein, I. Hijiya-Kirschnereit, C. Gersdorf, and E. Giannoulis (eds), The Cultural Career of Coolness: Discourses and Practises of Affect Control In European Antiquity, The United States And Japan, Plymouth: Lexington Books, pp. 113-30. 
Edwards, B. (1961), Breakfast at Tiffany's, USA: Paramount Pictures.

Edwards, O. (1989), 'Shades of meaning', American Photographer, no. 23, July, pp. 57-59.

Finnane, G. (2009), 'Holly Golightly and the fashioning of the waif', in P. MacNeil, V.

Karaminas, and C. Cole (eds), Fashion in Fiction: Text and Clothing in Literature, Film and Television, Oxford: Berg, pp. 137-48.

Fraimen, S. (2003), Cool Men and the Second Sex, New York: Columbia University Press.

Frank, T. (1997), The Conquest of Cool, Chicago: University of Chicago Press.

French, L. (2016), 'Shopping for identity: Postfeminist Flâneuses in Sex in the City and In the Cut', in A. Hulme (ed.), Consumerism on TV: Popular Media from the 1950s to the Present, London: Routledge, pp. 147-62.

Gergen, K. (1991), The Saturated Self, New York: Basic Books.

Gill, R. (2016), 'Post-postfeminism?: New feminist visibilities in postfeminist times', Feminist Media Studies, 16:4, pp. 610-30. 
Godard, Jean-Luc (1960) A Bout de Souffle France: Les Films Imperia.

Goffman, E. (1963), Behaviour in Public Places, New York: Free Press.

_[1967] 2005), Interaction Ritual, New Jersey: Aldine Transaction.

Gundle, S. (2008), Glamour - A History, Oxford: Oxford University Press.

Hatch, K. (2002) 'Fille fatale' in F. Gateward and M. Pomerance (eds), Sugar, Spice and Everything Nice, Detroit, Wayne State University Press.

Heyl, C. (2001), 'When they are veiled in order to be seene' in J.Entwistle and E.Wilson (eds), Body Dressing, Oxford, Berg, pp. 121-142

hooks, b. (2003), We Real Cool: Black Men and Masculinity, London: Routledge.

Haselstein, U. (2013), 'The cultural career of coolness', in U. Haselstein, I. HijiyaKirschnereit, C. Gersdorf and E. Giannoulis (eds), The Cultural Career of Coolness: 
Discourses and Practises of Affect Control In European Antiquity, The United States And Japan, Plymouth: Lexington Books, pp. 64-84.

Hobdy, D. (2016), 'Black and proud: The most woke halloween costumes of 2016', Essence, 1 November, https://www.essence.com/fashion/woke-costumes-halloween-2016. Accessed 8 February 2018.

Hughey, M. W. (2009), 'Black aesthetics and panther rhetoric: A critical decoding of black masculinity in The Black Panther, 1967-80’, Critical Sociology, 35:1, pp. 29-56.

IMDB (Internet Movie Database) (2014) 'Mysterious Skin', https://www.imdb.com/title/tt0370986/. Accessed 15/06/18.

Kubrick, S. (1962), Lolita, USA: Metro-Goldwyn-Mayer.

Laing, M. (2018), 'Rewriting Lolita in the fashion photograph: Candy, consumption and the dying flower', Sexualities, 30 January, pp. 1-22.

Lewis, C. Y. (2011), 'Cool postfeminism: The stardom of Sofia Coppola', in D. Negra and S. Holmes (eds), In the Limelight and Under the Microscope: Forms and Functions of Female Celebrity, New York: Bloomsbury Academic, pp 174-198. 
Liu, A. (2004), The Laws of Cool: Knowledge Work and the Culture of Information, Chicago: University of Chicago Press.

Macadams, L. (2002), Birth of the Cool: Beat, Bebop and the American Avant-Garde, London: Scribner.

Majors, R. and Billson, J. (1992), Cool Pose: The Dilemmas of Black Manhood in America, New York: Simon and Schuster.

McGuigan, J. (2013), 'Cool capitalism at work', in U. Haselstein, I. Hijiya-Kirschnereit, C. Gersdorf, and E. Giannoulis (eds), The Cultural Career of Coolness: Discourses and Practises of Affect Control In European Antiquity, The United States And Japan, Plymouth: Lexington Books, pp. 265-84.

Mentges, G. (2000), 'Cold, coldness, coolness: Remarks on the relationship of dress, body and technology', Journal of Fashion Theory, 4:1, pp. 27-47.

Mercer, K. ([1987] 1997), 'Black hair/style politics', in K. Gelder and S. Thornton (eds), The Subcultures Reader, London, Routledge, pp. 420-35. 
Merton, R. K. (1967), Social Theory and Social Structure, New York: The Free Press.

Michael, J. (2015), 'It's really not hip to be a hipster: Negotiating trends and authenticity in the cultural field', Journal of Consumer Culture, 15:2, pp. 163-82.

Miller, J. (ed.) (2014), 'Audrey is a hepcat now', in Fan Phenomena: Audrey Hepburn, Chicago: University of Chicago Press, pp. 20-27.

Mosely, R. (2002), ‘Trousers and tiaras: Audrey Hepburn, a woman's star', Feminist Review, 71, pp. 37-51.

Nelson, S. (2016), The Black Panthers: Vanguard of the Revolution, USA: Firelight Films.

O’Hagan, S. (2009), 'Life with the black panthers', The Guardian, 29 October, https://www.theguardian.com/artanddesign/2009/oct/25/black-panthers-photographs-howardbingham. Accessed 05/03/2015.

Postrel, V. (2013), The Power of Glamour, London: Simon and Schuster. 
Pountain, D. and Robins, D. (1999), 'Cool rules: Anatomy of an attitude', New Formations 39, pp. 7-14.

(2000), Cool Rules: Anatomy of an Attitude, London: Reaktion Books.

Phu, T. N. (2008), 'Shooting the movement: Black Panther party photography and African American protest traditions', Canadian Review of American Studies, 38:1, pp. 165-89.

Radner, H. (2013), 'On the move: Fashion photography and the single girl in the 1960s', in S.

Bruzzi and P. Church-Gibson (eds), Fashion Cultures: Theories, Explanations, Analysis, London: Routledge, pp. 128-42.

Raiford, L. (2011), Imprisoned in a Luminous Glare: Photography and the African American Freedom Struggle, North Carolina, University of North Carolina Press.

Rhodes, J. (2017), Framing the Black Panthers - the Spectacular Rise of a Black Power Icon, Urbana, Chicago and Springfield: University of Illinois Press.

Roelstrate, D. (2010), 'Modernism, postmodernism and gleam: On the photorealist work ethic', Afterall, no. 24, https://www.afterall.org/journal/issue.24/modernismpostmodernism.and.gleamon.the.photore alist.work.ethic. Accessed 04/04/2013. 
Shields, R. (1994), 'Fancy footwork: Walter Benjamin's notes on flaneurie' in K.Tester (ed), The Flaneur, London: Routledge, pp.61-80.

Simmel, G. ([1903] 1964), The Sociology of Georg Simmel, London: Collier-Macmillan.

Stacey, J. (1994), Star Gazing - Hollywood Cinema and Female Spectatorship, London: Routledge.

_ (2015), 'Crossing over with Tilda Swinton: The mistress of "Flat Affect"', International Journal of Politics, Culture, and Society, 28:3, pp. 243-271.

Stearns, P. (1994), American Cool, New York: New York University Press.

Tate, G. (2003), Everything But the Burden - What White people are taking from Black Culture, New York: Harlem Mon, Broadway Books.

Unwerth, E. van (1992), 'Charming Lolita', Vogue Italia, April, n.pag. 
Vickers, G. (2008), Chasing Lolita, Chicago: Chicago Review Press.

Walden, G. (2002), Who Is a Dandy?, London: Gibson Square Books.

Willson, J. (2015), Being Gorgeous: Feminism, Sexuality and the Pleasures of the Visual, London: I.B. Tauris.

Wilson, G. (1999), 'The psychology of specs and shades', unpublished study commissioned by Brook Wilkinson on behalf of Dolland and Aitchison.

\section{Contributor details}

Dr Vanessa Brown is Senior Lecturer in the School of Art and Design, Nottingham Trent University, where she is author of and course leader for MA Culture, Style \& Fashion and a $\mathrm{PhD}$ supervisor, having also dedicated significant time to developing innovative strategies for teaching critical and contextual Studies to students of fashion and textile design. She has a background in both practical design and cultural studies. She is the author of Cool Shades: The History and Meaning of Sunglasses (2015).

Contact:

E-mail: vanessa.brown@ntu.ac.uk

https://orcid.org/0000-0002-0855-920X 
${ }^{1}$ Publication of the images here has not been possible due to lack of response from copyright holders and current copyright legislation, but suggested links are provided as endnotes.

${ }^{2}$ The opening sequence may be viewed at https://www.youtube.com/watch?time_continue=14\&v=1JfS90u-1g8.

${ }^{3}$ The monochrome still of Audrey gazing into the window of Tiffany's can be viewed at https://www.imdb.com/title/tt0054698/mediaviewer/rm3436642816.

${ }^{4}$ The original film poster can be viewed at https://www.imdb.com/title/tt0054698/mediaviewer/rm3522705920.

${ }^{5}$ For example, an image sold at the time of writing on Redbubble; see https://www.redbubble.com/people/edwardiano82/works/15944870-breakfast-at-tiffanys. ${ }^{6}$ The original film poster for Lolita is available at https://www.imdb.com/title/tt0056193/mediaviewer/rm192340224.

${ }^{7}$ See one of Lana Del Rey's Lolita pastiches at https://www.imdb.com/title/tt7078560/mediaviewer/rm3564184576.

${ }^{8}$ On sale at the time of writing at https://lespecs.com/the-last-lolita-1502112-opaque-redsilver-mirror-las1502112.

${ }^{9}$ Available at https://www.last.fm/music/Kathleen+Cleaver.

${ }^{10}$ Film poster available at http://theblackpanthers.com/home/. 